Article

\title{
Effects of a Carbon Nanotube Additive on the Corrosion-Resistance and Heat-Dissipation Properties of Plasma Electrolytic Oxidation on AZ31 Magnesium Alloy
}

\author{
Myungwon Hwang and Wonsub Chung * \\ Department of Materials Science and Engineering, Pusan National University, Busan 609-735, Korea; \\ mwhwang@pusan.ac.kr \\ * Correspondence: wschung1@pusan.ac.kr; Tel.: +82-51-510-2386
}

Received: 9 November 2018; Accepted: 30 November 2018; Published: 2 December 2018

check for updates

\begin{abstract}
Plasma electrolytic oxidation (PEO) coating was obtained on AZ31 Mg alloy using a direct current in a sodium silicate-based electrolyte with and without a carbon nanotube (CNT) additive. The surface morphology and phase composition of the PEO coatings were investigated through field emission scanning electron microscopy (SEM), X-ray diffraction (XRD), and X-ray photoelectron spectroscopy (XPS). The corrosion-resistance properties of the PEO coatings were evaluated using potentiodynamic polarization measurements and electrochemical impedance spectroscopy (EIS) in a $3.5 \mathrm{wt} . \% \mathrm{NaCl}$ solution. Furthermore, the heat-dissipation property was evaluated by a heat-flux measurement setup using a modified steady-state method and Fourier transform infrared spectroscopy (FT-IR). The results demonstrate that, by increasing the concentration of CNT additive in the electrolyte, the micropores and cracks of the PEO coatings are greatly decreased. In addition, the anticorrosion performance of the PEO coatings that incorporated CNT for the protection of the $\mathrm{Mg}$ substrate was improved. Finally, the coating's heat-dissipation property was improved by the incorporation of CNT with high thermal conductivity and high thermal emissivity.
\end{abstract}

Keywords: magnesium alloy; plasma electrolytic oxidation; carbon nanotube; corrosion resistance; emissivity

\section{Introduction}

Magnesium alloys have been widely used in the automobile, aerospace, and electronics industries due to their low density, high specific strength, specific stiffness, castability, and machinability [1,2]. However, they also have important constraints due to their poor corrosion resistance, which is caused by low active electrochemical potential. To overcome this limitation, surface-treatment techniques, such as physical vapor deposition (PVD), thermal spraying, and anodizing, have been developed [3-5].

Plasma electrolytic oxidation (PEO), a typical surface-treatment technology based on conventional anodization, is environmentally friendly and economical [6-8]. Ceramic-like oxide coating is formed on the magnesium substrate to improve corrosion and abrasion resistance. Since PEO proceeds above the breakdown voltage, a microarc occurs on the surface of the oxide film, and the oxide film is locally melted and mixed with electrolyte ions. Using these process features, various additives have been used to improve the performance of the coating. Composite PEO can be divided into two types: it either uses a water-soluble additive or an insoluble additive [9]. The former is used in the form of an aqueous solution, mixed with basic electrolytes, and the latter is formed by adding insoluble microand nanosized particles to the electrolyte to form a composite PEO coating. 
Heat transfer is classified into three main mechanisms, thermal conduction, thermal convection, and thermal radiation [10]. A heatsink cooled by natural convection uses the conduction and radiation mechanisms. An oxide coating is generally applied to improve the heat-dissipation capabilities of the heatsink [11-13]. Many studies have been carried out to optimize shape and material to improve thermal conductivity [14-16]. However, heat dissipation using radiation only uses conventional anodizing, and research on the improvement of heat-dissipation performance through high emissivity is insufficient. The heatsink with high emissivity is advantageous for the miniaturization and weight reduction of the product by ensuring sufficient heat-dissipation capacity with a small volume. It is also advantageous to reduce cost by using few raw materials.

In this paper, a carbon nanotube (CNT) with excellent emissivity and thermal conductivity was incorporated into the oxide film to produce coatings with excellent heat-dissipation capabilities. Radiation heat dissipation can be expressed with a modified Stefan-Boltzmann law as [17,18]:

$$
\mathrm{E}=\varepsilon \times \sigma \times\left(\mathrm{T}_{\mathrm{h}}{ }^{4}-\mathrm{T}_{\mathrm{C}}^{4}\right) \times \mathrm{A}
$$

where $\mathrm{E}, \varepsilon, \sigma, \mathrm{T}_{\mathrm{h}}, \mathrm{T}_{\mathrm{c}}$, and $\mathrm{A}$ are radiative dissipated heat energy, emissivity $(0 \leq \varepsilon \leq 1)$, Stefan-Boltzmann constant $\left(5.6703 \times 10^{-8} \mathrm{~W} / \mathrm{m}^{2} \cdot \mathrm{K}^{4}\right)$, hot-body absolute temperature $(\mathrm{K})$, cold-surroundings absolute temperature $(\mathrm{K})$, and the surface area of the object $\left(\mathrm{m}^{2}\right)$, respectively. In other words, emissivity is a major factor in the heat transfer using the radiation mechanism. When emissivity is close to 1 , as in the case of a black body, the heat-dissipation property due to radiation increases and can be applied to a heat sink.

The emissivity of $\mathrm{MgO}$ is 0.68 , which shows somewhat low emissivity [19]. On the other hand, CNT shows 0.98 emissivity, close to that of a black body [20]. Therefore, if CNT is embedded in oxide film with composite PEO, it can allow the oxide film to have high corrosion resistance and emissivity.

\section{Experimental Procedure}

A plate, sized $40 \times 80 \times 2 \mathrm{~mm}$, of AZ31 Mg alloy was used for all experiments. The samples were polished with $\mathrm{SiC}$ paper to approximately 1200 , washed with distilled water at room temperature, and ultrasonically cleaned in ethanol. The area except for the area of $40 \times 40 \mathrm{~mm}$ where the PEO treatment is to be performed were masked with a heat-resistant insulating tape.

A schematic view of the electrolytic cell is depicted in Figure 1. A DC supply of $2.4 \mathrm{~kW}$ (600 V-4 A) was used, and 304 stainless steel was used as a counter-electrode. The composition of the electrolytic solution is shown in Table 1. Each electrolyte solution was stirred at $400 \mathrm{rpm}$ with a magnetic stirrer for $60 \mathrm{~min}$ before the experiment. At the same time, the CNT (Multiwalled CNT, Carbon Nanomaterial Technology, Pohang-si, Korea) was uniformly dispersed physically by a horn-type ultrasonicator (ULH-700S, Sibata, Soka-shi, Japan). The temperature of the electrolyte was maintained at $20 \pm 2{ }^{\circ} \mathrm{C}$ through the chiller (DA-1000B, Daeil, Busan-si, Korea). The PEO process maintained 10 amperes per square decimeter (ASD) through the electrostatic method. The voltage change over time was measured by a multimeter (FLUKE 289, FLUKE, Everett, WA, USA) throughout the PEO process. After the PEO process, the sample was washed with distilled water.

The surface morphology and cross-sectional views of the coated samples were observed using a field-emission scanning electron microscope (FE-SEM, Mira 3, Tescan, Brno, Czech Republic). Qualitative phase analysis was performed with X-ray diffraction (XRD, Ultima IV, Rigaku, Akishima-shi, Japan) using a $\mathrm{Cu}$ target in the range of 20 to 80 degrees. The chemical state was analyzed using X-ray photoelectron spectroscopy (XPS, Sigma Probe, Thermo Fisher Scientific, Waltham, MA, USA).

All electrochemical experiments were carried out using a $250 \mathrm{~mL}$ flat cell with three electrode structures. Platinum sheets of $30 \times 30 \mathrm{~mm}^{2}$ and saturated calomel electrodes (SCE) were used as counter-electrodes and reference electrodes, respectively. In the $3.5 \mathrm{wt} . \% \mathrm{NaCl}$ solution, the working electrode was exposed in an area of $1 \mathrm{~cm}^{2}$, and the experiment proceeded at room temperature. 


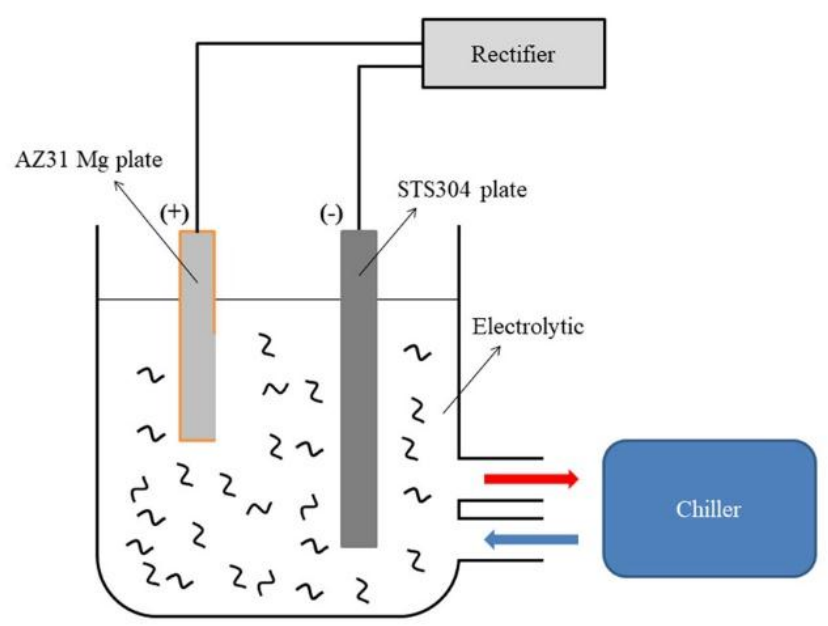

Figure 1. Schematic diagram of the experimental setup used for plasma electrolytic oxidation.

Table 1. Specification of the electrolytes for the plasma electrolytic oxidation (PEO) process in AZ31 $\mathrm{Mg}$ alloy.

\begin{tabular}{ccccccc}
\hline Sample & $\mathrm{CNT}(\mathrm{g} / \mathrm{L})$ & $\mathrm{KOH}(\mathrm{g} / \mathrm{L})$ & $\mathrm{KF}(\mathrm{g} / \mathrm{L})$ & $\mathrm{Na}_{2} \mathrm{SiO}_{3}(\mathrm{~g} / \mathrm{L})$ & $\mathrm{pH}$ & Conductivity \\
\hline $0 \mathrm{~g} / \mathrm{L} \mathrm{CNT}$ & 0 & 2 & 2 & 6 & 12.3 & 13.7 \\
$2.5 \mathrm{~g} / \mathrm{L} \mathrm{CNT}$ & 2.5 & 2 & 2 & 6 & 12.3 & 14.8 \\
$5 \mathrm{~g} / \mathrm{L} \mathrm{CNT}$ & 5 & 2 & 2 & 6 & 12.3 & 16.4 \\
$10 \mathrm{~g} / \mathrm{L} \mathrm{CNT}$ & 10 & 2 & 2 & 6 & 12.3 & 18.1 \\
\hline
\end{tabular}

The potentiodynamic polarization experiment was performed using Versastat4 (Ametek, France). Before carrying out the potentiodynamic experiment, it was held for about $10 \mathrm{~min}$ to stabilize the open-circuit potential (OCP). The polarization curves were obtained in the range of $-1.2 \mathrm{~V} / \mathrm{SCE}$ to $1 \mathrm{~V} / \mathrm{SCE}$, and the experiment was performed at a scan rate of $1.67 \mathrm{mV} / \mathrm{s}$. Electrochemical Impedance Spectroscopy (EIS) experiments were performed using IM6 (ZAHNER-Electrick, Kronach, Germany). The EIS experiments were carried out after stabilization in the electrolytic solution for about $30 \mathrm{~min}$. The test was performed in the frequency range of $100 \mathrm{kHz}$ to $0.01 \mathrm{~Hz}$ under the condition of applying an AC voltage of $10 \mathrm{mV}$ to the OCP.

The heat flux was measured with an apparatus used in a previous study, and the heat-flux instrument is shown in Supplementary Figure S1 [21]. Moreover, Fourier transform infrared spectroscopy (FT-IR, Nicolet 360, Thermo Fisher Scientific, Waltham, MA, USA) was used to measure the emissivity for thermal-radiation performance at $100{ }^{\circ} \mathrm{C}$.

\section{Results and Discussion}

\subsection{Plasma Electrolytic Oxidation Process}

As described in Table 1, the $\mathrm{pH}$ was constant regardless of the amount of CNT added, and the electrical conductivity of the electrolyte increased from 13.7 to $18.1 \mathrm{mS} / \mathrm{cm}$ as high-conductivity CNT was added. Dispersion of CNT from the electrolyte was affected by zeta potential. The isoelectric point of $\mathrm{CNT}$ was $4.5 \mathrm{pH}$ [22]. The zeta potential increased with increasing $\mathrm{pH}$ [23]. An increase in the absolute value of the zeta potential causes electrostatic repulsion between the particles and improves dispersion stability. The zeta potential of CNT dispersed with the silicate-based electrolyte was negatively charged at $-66.8 \mathrm{mV}$, and stable dispersion was achieved. Therefore, negatively charged CNT was attracted to the positive electrode and incorporated into the film during the PEO process. 


\subsection{Morphology and Structure of PEO Coatings}

Figure 2 shows voltage change over time during the PEO process along with the concentration of CNT in the electrolyte. The change in voltage over time can be explained in three stages [24]. The first stage is when voltage increases rapidly. At this time, a transparent passive film acting as an electrical insulator grows rapidly. The second stage is when the slope of the voltage drops rapidly, and the breakdown voltage appears. Microdischarge starts to occur after the appearance of the breakdown voltage. The third stage is when a large-scale arc occurs with a stable slope. Regardless of the amount of added CNT, the voltage-response behavior remained similar over time in the first stage. However, in the second and third stages, as the CNT amount was increased, breakdown voltage lowered rapidly, and the voltage reaching equilibrium was also lower. Since breakdown voltage is influenced by the electrolyte, the electrical conductivity of the electrolyte is increased by adding CNT, and breakdown voltage is decreased $[25,26]$. In addition, it is presumed that voltage fluctuation is formed by electrophoresis and physical stirring of CNT.

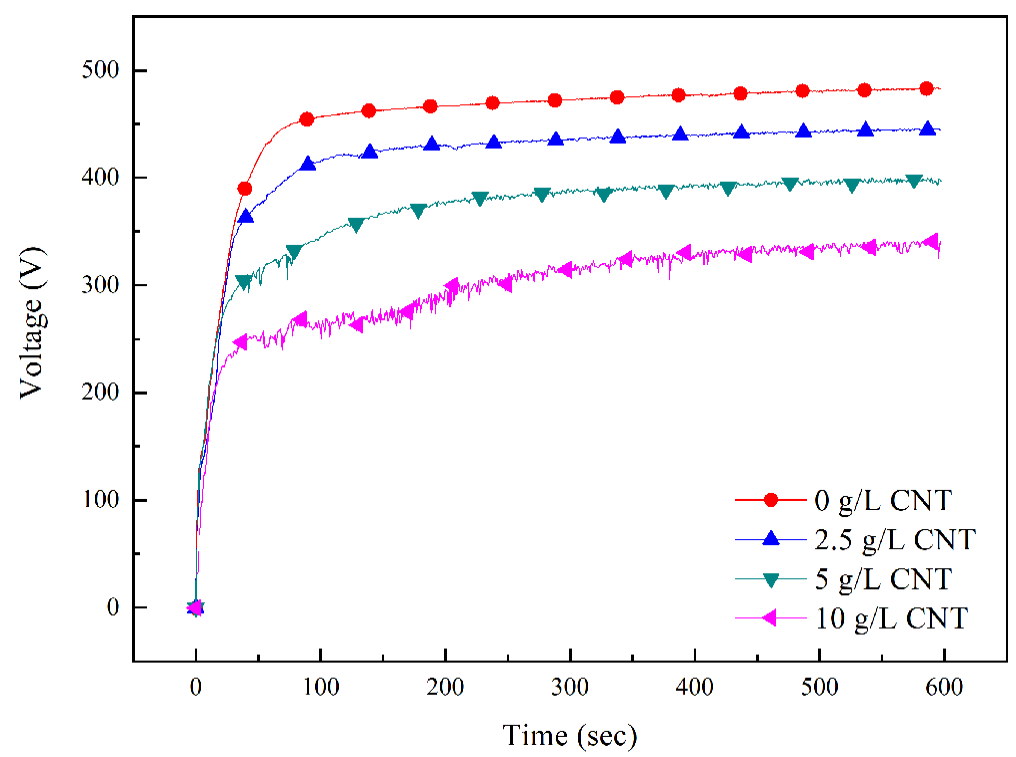

Figure 2. Voltage-time response during the PEO process at different concentration of carbon nanotube (CNT).

Figure 3 is an optical photograph of the sample according to the amount of CNT added. Samples without addition of CNT are white and gradually darken with addition of CNT. When the CNT concentration of the electrolyte is $10 \mathrm{~g} / \mathrm{L}$, the surface of the sample is black. It can be seen that the color of the PEO coating changes depending on the amount of CNT incorporation.
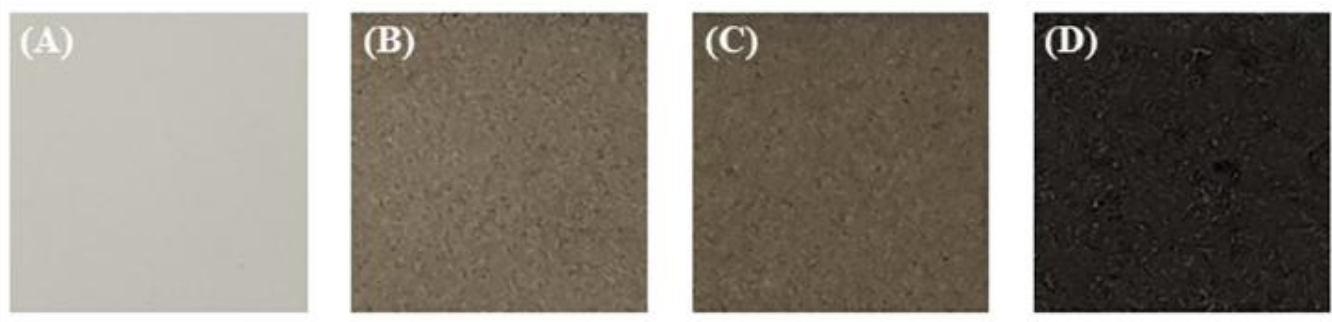

Figure 3. Optical images of the PEO coatings formed in the electrolytes containing different amounts of CNT: (A) $0 \mathrm{~g} / \mathrm{L} \mathrm{CNT;} \mathrm{(B)} 2.5 \mathrm{~g} / \mathrm{L} \mathrm{CNT;} \mathrm{(C)} 5 \mathrm{~g} / \mathrm{L} \mathrm{CNT}$ and (D) $10 \mathrm{~g} / \mathrm{L} \mathrm{CNT.}$ 
The surface morphologies of coatings formed on AZ31 Mg alloy specimens at different concentrations of CNT are shown in Figure 4. The PEO coating without CNT shows a typical porous structure with some bulges on the surface [27]. Surface pores are formed by the solidifying oxide film melted by the microarcs including spherical gas bubbles [28]. Microcracks in the PEO coatings occur due to thermal stresses during coating formation as a result of the melting and solidification of ceramic compounds, such as $\mathrm{MgO}$ and $\mathrm{Mg}_{2} \mathrm{SiO}_{4}[29,30]$. Figure $4 \mathrm{~d}$ shows the surface morphology of the PEO coating with $10 \mathrm{~g} / \mathrm{L}$ CNT additive. Due to the high electrical conductivity of the CNTs in the electrolyte, breakdown voltage and working voltage are significantly reduced, and a small microarc is generated. As a result, the porosity and size of the microcracks decreased. It was also seen that the thermal stress was reduced by the weak discharge, and the cracks in the coating layer were reduced. Accordingly, the structure of the oxide film became much finer. The high-magnification SEM micrograph of inset Figure $4 \mathrm{~d}$ indicates the incorporation of CNT around the pores.
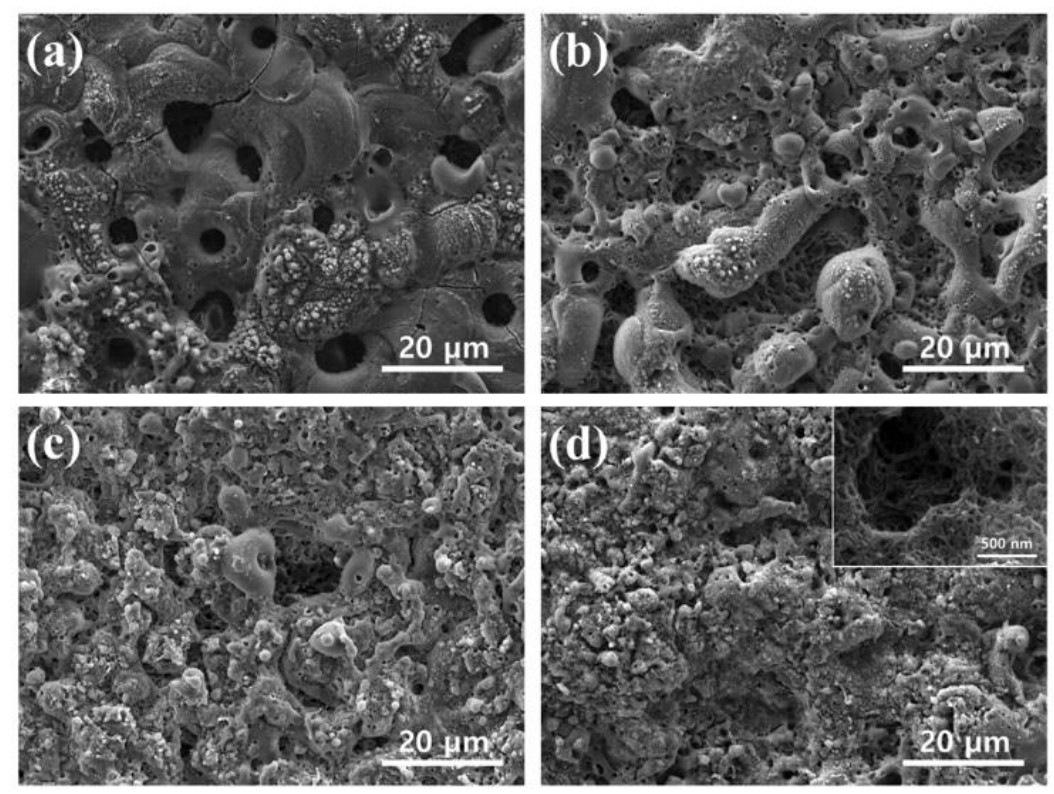

Figure 4. Scanning electron microscopy (SEM) micrographs of the surface morphologies of PEO coatings in different concentration of CNT: (a) $0 \mathrm{~g} / \mathrm{L} \mathrm{CNT;} \mathrm{(b)} 2.5 \mathrm{~g} / \mathrm{L} \mathrm{CNT;} \mathrm{(c)} 5 \mathrm{~g} / \mathrm{L} \mathrm{CNT;}$ and (d) $10 \mathrm{~g} / \mathrm{L} \mathrm{CNT}$; the inset is the SEM image of the incorporated CNT.

Figure 5 shows the SEM cross-sectional images of the PEO coatings processed in electrolytes containing different concentration of CNT additive. The cross-sectional morphology of the PEO coating consists of three parts: outer porous layer, pore band, and inner dense layer at the substrate/coating interface [31]. Pore bands can be formed between the outer and inner layer of PEO coating using the direct current mode [32]. The average thickness of the coating layer decreased to 19.3,14.2, 12.5, and $8.0 \mu \mathrm{m}$ as the addition amount of CNT increased to $0,2.5,5$, and $10 \mathrm{~g} / \mathrm{L}$, respectively. It seems that the thickness of the coating layer was thinned by the low energy input due to the low operating voltage during the PEO process. In addition, the film that is formed by the small microarc generated by the addition of CNT appears to have a denser structure. In general, the corrosion of the PEO coating occurs when corrosive substances reach the $\mathrm{Mg}$ substrate through pores or microcracks and form a large amounts of $\mathrm{Mg}(\mathrm{OH})_{2}$. As the volume of $\mathrm{Mg}(\mathrm{OH})_{2}$ is larger than that of $\mathrm{MgO}$, the interface causes cracking and promotes corrosion [33]. The insoluble additive in the PEO coating exhibits a self-sealing effect for the micropores and cracks in the coating [34]. CNT present in pores and microcracks is likely to inhibit the evolution of corrosive ions. 

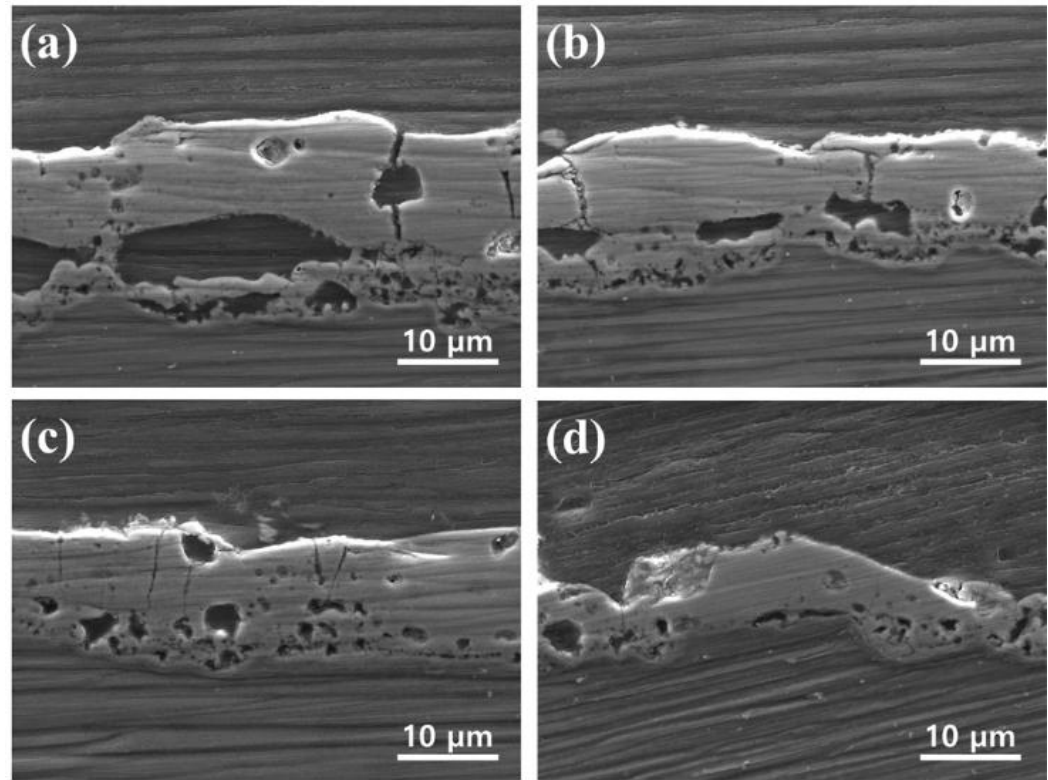

Figure 5. Cross-sectional SEM images of PEOcoated specimens formed in the electrolytes containing different amounts of CNT: (a) $0 \mathrm{~g} / \mathrm{L} \mathrm{CNT;} \mathrm{(b)} 2.5 \mathrm{~g} / \mathrm{L} \mathrm{CNT;} \mathrm{(c)} 5 \mathrm{~g} / \mathrm{L} \mathrm{CNT}$; and (d) $10 \mathrm{~g} / \mathrm{L} \mathrm{CNT}$.

\subsection{Phase Analysis and Chemical State of PEO Coatings}

X-ray diffraction patterns of PEO coating samples with and without CNT additives and uncoated AZ31 Mg alloy substrates are illustrated in Figure 6. Since an X-ray can easily penetrate the porous oxide layer, a strong diffraction peak of the $\mathrm{Mg}$ substrate was detected in all samples. The main phases of oxide films were composed of $\mathrm{MgO}$ and $\mathrm{Mg}_{2} \mathrm{SiO}_{4}$ phases in the silicate-based electrolyte [24,35]. $\mathrm{MgO}$ forms on the surface of magnesium substrates under high temperatures and a strong electric field, as shown by the following anodic reaction [36].

$$
\begin{gathered}
\mathrm{Mg} \rightarrow \mathrm{Mg}^{2+}+2 \mathrm{e}^{-} \\
\mathrm{H}_{2} \mathrm{O} \rightarrow \mathrm{O}_{2}+4 \mathrm{H}^{+}+4 \mathrm{e}^{-} \\
\mathrm{Mg}^{2+}+2 \mathrm{OH}^{-} \rightarrow \mathrm{Mg}(\mathrm{OH})_{2} \\
\mathrm{Mg}(\mathrm{OH})_{2} \rightarrow \mathrm{MgO}+\mathrm{H}_{2} \mathrm{O}
\end{gathered}
$$

$\mathrm{Mg}_{2} \mathrm{SiO}_{4}$ phases in a silicate-based electrolyte are produced according to the following equations:

$$
\mathrm{Mg}^{2+}+2 \mathrm{SiO}_{3}{ }^{2-} \rightarrow \mathrm{Mg}_{2} \mathrm{SiO}_{4}+\mathrm{SiO}_{2}
$$

In addition, molten $\mathrm{MgO}$ reacts with molten $\mathrm{SiO}_{2}$ to form $\mathrm{Mg}_{2} \mathrm{SiO}_{4}$ in the $\mathrm{PEO}$ ambient.

$$
\begin{gathered}
\mathrm{SiO}_{3}{ }^{2-}+2 \mathrm{H}^{+} \rightarrow \mathrm{SiO}_{2}+\mathrm{H}_{2} \mathrm{O} \\
2 \mathrm{SiO}_{3}{ }^{2-} \rightarrow \mathrm{O}_{2}+2 \mathrm{SiO}_{2}+4 \mathrm{e}^{-} \\
\mathrm{SiO}_{2}+2 \mathrm{MgO} \rightarrow \mathrm{Mg}_{2} \mathrm{SiO}_{4}+\mathrm{SiO}_{2}
\end{gathered}
$$

There is no CNT signal detected in the XRD pattern, due to the small amount of CNT incorporation. Furthermore, the CNT addition seems to have a negligible effect on the phase composition of the PEO coating. 


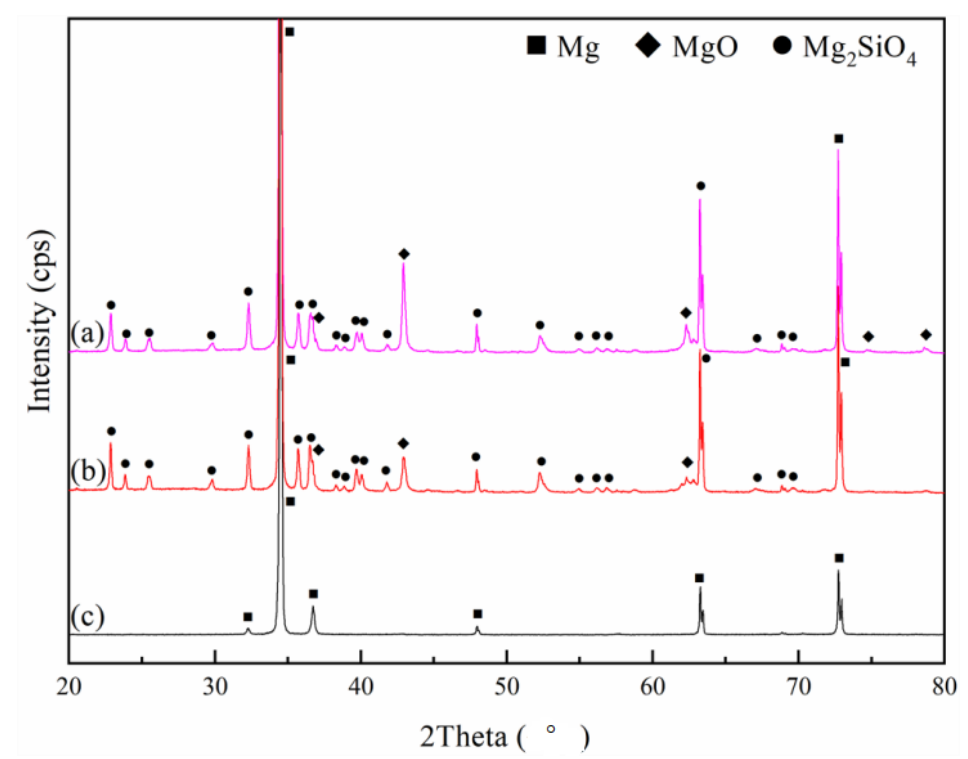

Figure 6. X-ray diffraction (XRD) patterns of PEO coatings and substrate: (a) $10 \mathrm{~g} / \mathrm{L}$ CNT PEO coating; (b) 0 g/L CNT PEO-coating; and (c) AZ31 Mg substrate.

Figure 7 show the XPS spectra of the PEO coatings formed in an electrolyte with and without $10 \mathrm{~g} / \mathrm{L} \mathrm{CNT}$ additive. The XPS spectra detected $\mathrm{Mg}, \mathrm{O}, \mathrm{Si}$, and $\mathrm{C}$ peaks. The $\mathrm{C} 1 \mathrm{~s}$ peak of the CNT-free coating seems to be hydrocarbon contamination inside the XPS vacuum chamber [37]. In the case of the CNT-added coating, it is shown that the $C 1$ s peak is significantly stronger than the PEO coating without $\mathrm{CNT}$, and this increase in peak intensity means that CNT can be incorporated into the oxide film through the PEO process. Figure 8 represents the high-resolution spectra of the $C 1$ s peak. Curve fitting was performed after a Shirley background subtraction by the mixed Gaussian-Lorentzian function. The $\mathrm{C} 1 \mathrm{~s}$ signals on the pristine $\mathrm{CNT}$ and the incorporated CNT in the PEO coating at 284.4-284.6, 284.9-285.3, 286.0-286.4, and 287.3-287.7 eV corresponded to $\mathrm{sp}^{2} \mathrm{C}=\mathrm{C}, \mathrm{sp}^{3} \mathrm{C}-\mathrm{C}, \mathrm{C}-\mathrm{O}$, and $\mathrm{C}=\mathrm{O}$ chemical bonding, respectively [38]. It was confirmed that $\mathrm{CNT}$ oxidation occurred during the $\mathrm{PEO}$ process due to the large increase of $\mathrm{C}-\mathrm{O}$ and $\mathrm{C}=\mathrm{O}$ signals compared to the signal of pristine CNT. The surface of the CNT was damaged by the excessive oxidation, and the length thereof was cut off, causing defects in the CNT that may lead to the deterioration of the CNT properties [39].

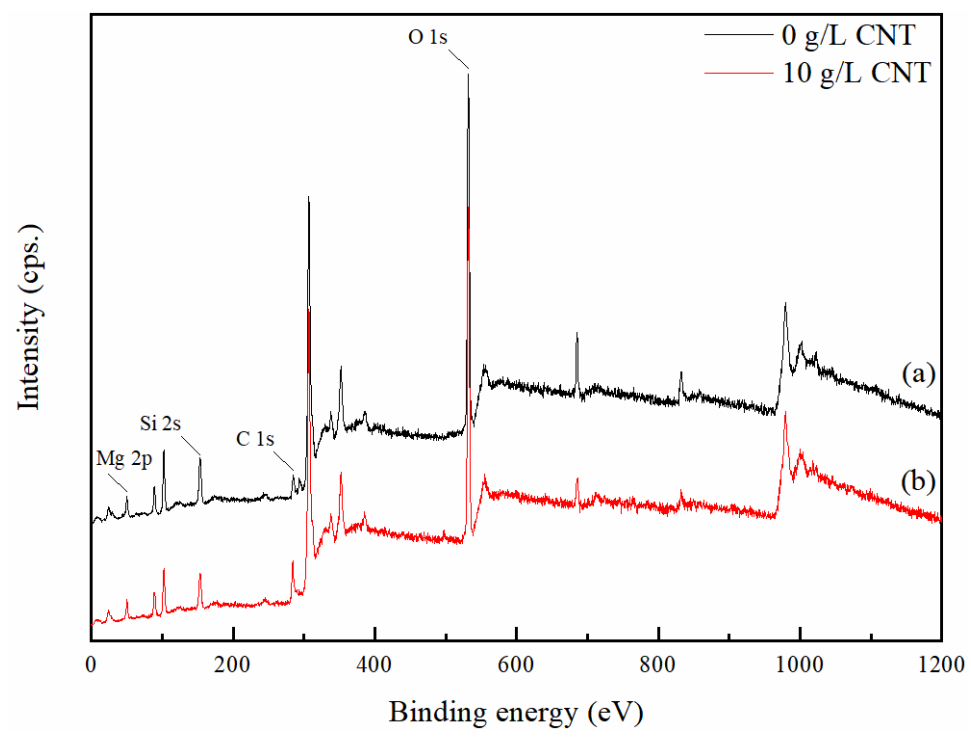

Figure 7. X-ray photoelectron spectroscopy (XPS) spectra of the PEO coatings in an electrolyte containing different concentration of CNT: (a) $0 \mathrm{~g} / \mathrm{L} \mathrm{CNT;} \mathrm{(b)} 10 \mathrm{~g} / \mathrm{L} \mathrm{CNT.}$ 

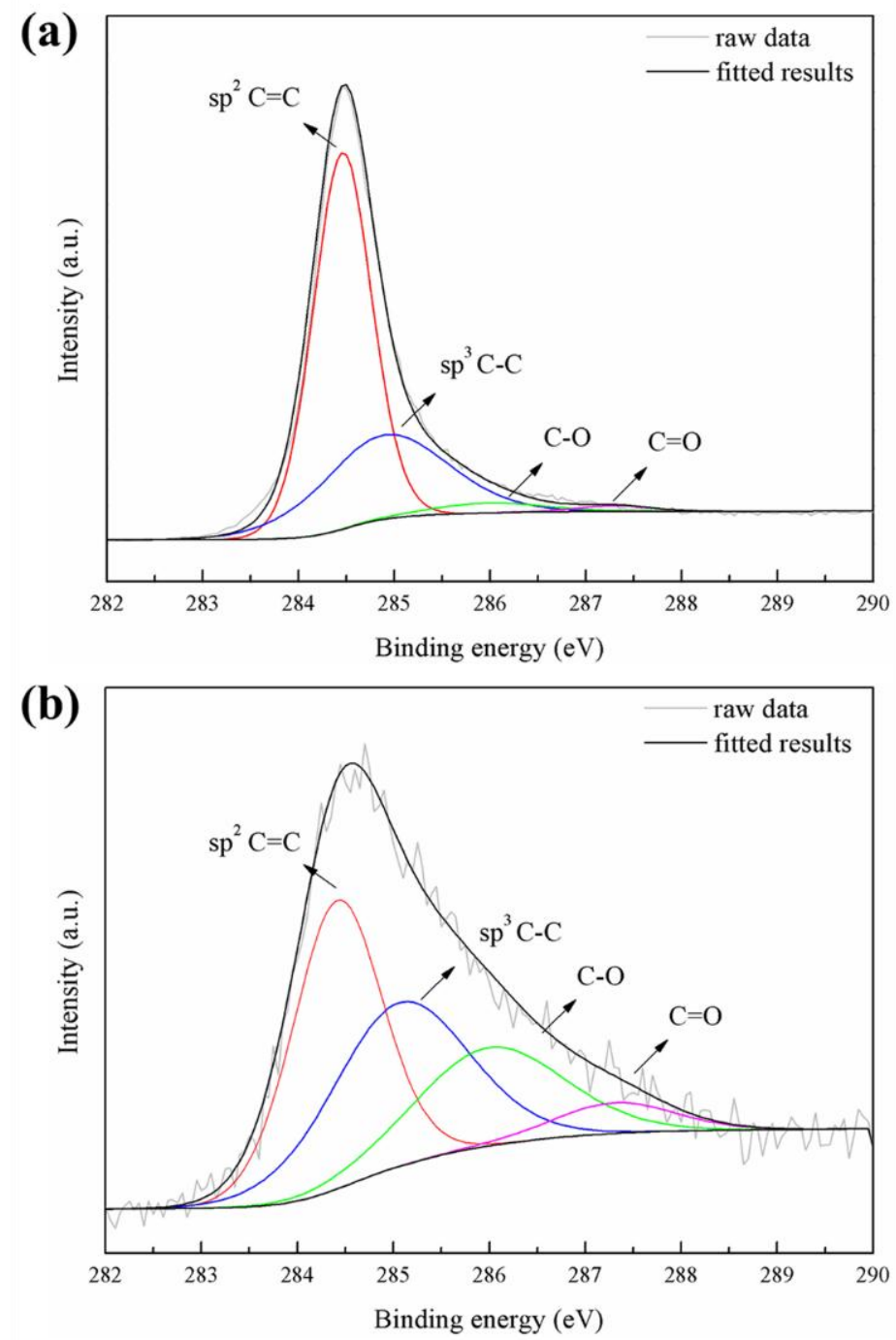

Figure 8. High-resolution XPS spectra of element-detected carbon: (a) pristine CNT and (b) $10 \mathrm{~g} / \mathrm{L}$ CNT PEO-coated film.

\subsection{Corrosion Behavior of PEO Coatings}

The potentiodynamic polarization curve of the AZ31 Mg alloy and the PEO coatings with different amounts of $\mathrm{CNT}$ additive in the electrolyte are shown in Figure 9. Corrosion potential ( $\left.\mathrm{E}_{\mathrm{corr}}\right)$, corrosion density ( $\left.\mathrm{i}_{\text {corr }}\right)$, and the Tafel slope were used to characterize the corrosion resistance of the samples. The high corrosion potential and low corrosion current density indicate the improving corrosion resistance of the oxide film. The electrochemical parameters derived by the Tafel extrapolation technique are presented in Table 2. From Table 2, we can see that AZ31 Mg alloy has poor corrosion resistance due to high corrosion current density $(-1.481 \mathrm{~V})$ and low corrosion potential $\left(1.12 \times 10^{-5} \mathrm{~A} / \mathrm{cm}^{2}\right)$. On the other hand, as CNT concentration of the electrolyte increased in the PEO process, corrosion resistance was highly improved. In particular, for samples with $10 \mathrm{~g} / \mathrm{L}$ CNT additive added to the electrolyte, the value of the corrosion current density was $4.80 \times 10^{-7} \mathrm{~A} / \mathrm{cm}^{2}$, a decrease of about two orders of magnitude relative to the uncoated AZ31 Mg alloy. These results demonstrate that the incorporation of a CNT additive into the oxide film improves the corrosion-resistance properties of the PEO coating. 


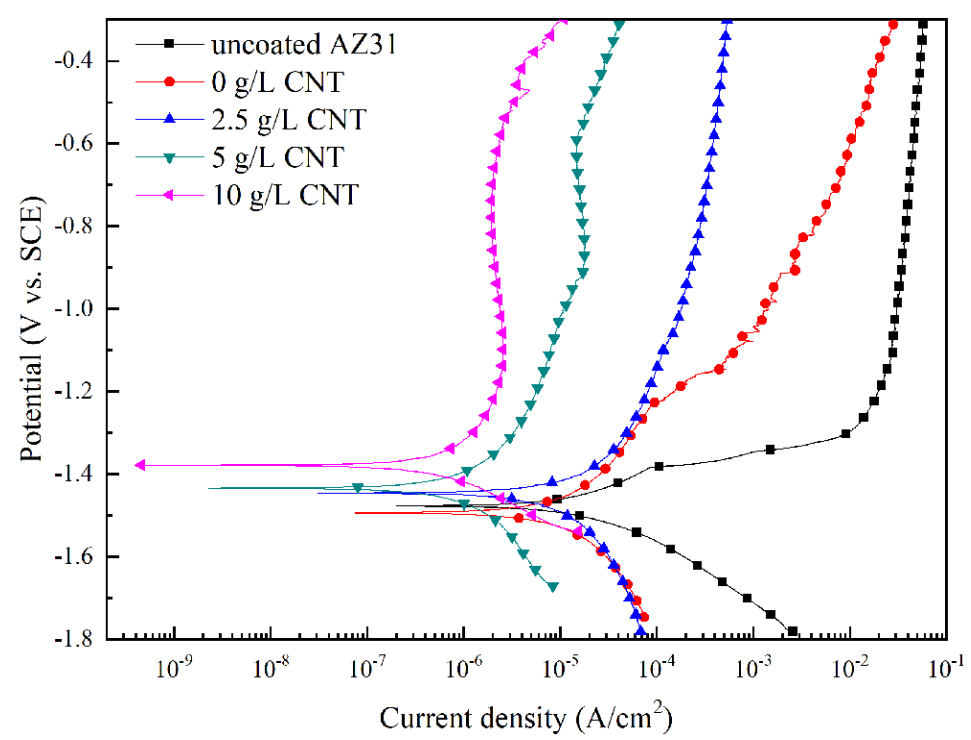

Figure 9. Potentiodynamic polarization curves of the PEO coatings formed in different CNT concentration of electrolytes.

Table 2. Tafel analysis results of uncoated and PEO-coated samples in an electrolyte containing different concentration of CNT.

\begin{tabular}{ccccc}
\hline Sample & Potential $(\mathbf{V})$ & Current $\left(\mathbf{A} / \mathbf{c m}^{\mathbf{2}}\right)$ & $\mathbf{b}_{\mathbf{a}}(\mathbf{m V})$ & $\mathbf{b}_{\mathbf{c}}(\mathbf{m V})$ \\
\hline uncoated AZ31 & -1.481 & $1.12 \times 10^{-5}$ & 94 & 82 \\
$0 \mathrm{~g} / \mathrm{L} \mathrm{CNT}$ & -1.493 & $7.14 \times 10^{-6}$ & 128 & 118 \\
$2.5 \mathrm{~g} / \mathrm{L} \mathrm{CNT}$ & -1.445 & $3.67 \times 10^{-6}$ & 55 & 100 \\
$5 \mathrm{~g} / \mathrm{L} \mathrm{CNT}$ & -1.473 & $1.43 \times 10^{-6}$ & 132 & 108 \\
$10 \mathrm{~g} / \mathrm{L} \mathrm{CNT}$ & -1.376 & $4.80 \times 10^{-7}$ & 146 & 111 \\
\hline
\end{tabular}

In order to understand more details about the corrosion behavior of the PEO coating in $3.5 \mathrm{wt} . \%$ $\mathrm{NaCl}$, EIS measurements were conducted. Figure 10 represents the Nyquist and Bode plots of uncoated AZ31 Mg substrate and PEO-coated samples with different amounts of CNT added into the electrolyte. As shown in Figure 10a, the Nyquist plot of the uncoated AZ31 Mg alloy shows a capacitive loop in the high-frequency range and an inductive loop in the low-frequency range. The Nyquist plot of the PEO-coated magnesium alloy shows two partially overlapped capacitive loops: a small one at lower frequencies and another at intermediate frequencies. Such behavior indicates the presence of two time constants. As the concentration of CNT increases, the radii of the two capacitive loops increase. As per the Bode plots in Figure 10b, the impedance value of the uncoated AZ31 Mg alloy was about $10^{2} \Omega \cdot \mathrm{cm}^{2}$ in the low-frequency region, and the impedance of the PEO coating in the same region was measured at about $10^{4} \Omega \cdot \mathrm{cm}^{2}$, and increased as high as 100 times. In particular, the impedance of the PEO-coating layer with the concentration of $10 \mathrm{~g} / \mathrm{L} \mathrm{CNT}$ additive in the electrolyte was $10^{5} \Omega \cdot \mathrm{cm}^{2}$, which is the highest value. The applied equivalent circuit is a widely applied model for ceramic-coated metal and consists of two time constants. $R_{S}$ is the solution resistance between the reference electrode and the working electrode, and $R_{\text {coat }}$ is the resistance due to the conduction flow of ions through the coating layer, connected in parallel with the constant phase element of the coating layer ( $\left.\mathrm{CPE}_{\mathrm{coat}}\right)$. $R_{\text {polar }}$, the polarization resistance at the coating layer-metal interface, is connected in parallel with the $\mathrm{CPE}_{\mathrm{dl}}$ of the double layer at the coating layer-metal interface. In this model, CPE represents admittance using a power fraction with nonideal behavior in systems with complex dispersion. The arc in the impedance spectra as a depressed semicircle is due to capacitance dispersion. It is appropriate to model with a CPE instead of an ideal capacitor. The admittance of a CPE can be expressed as [40]:

$$
\mathrm{Y}_{\mathrm{CPE}}(\omega)=1 / \mathrm{Z}_{\mathrm{CPE}}
$$



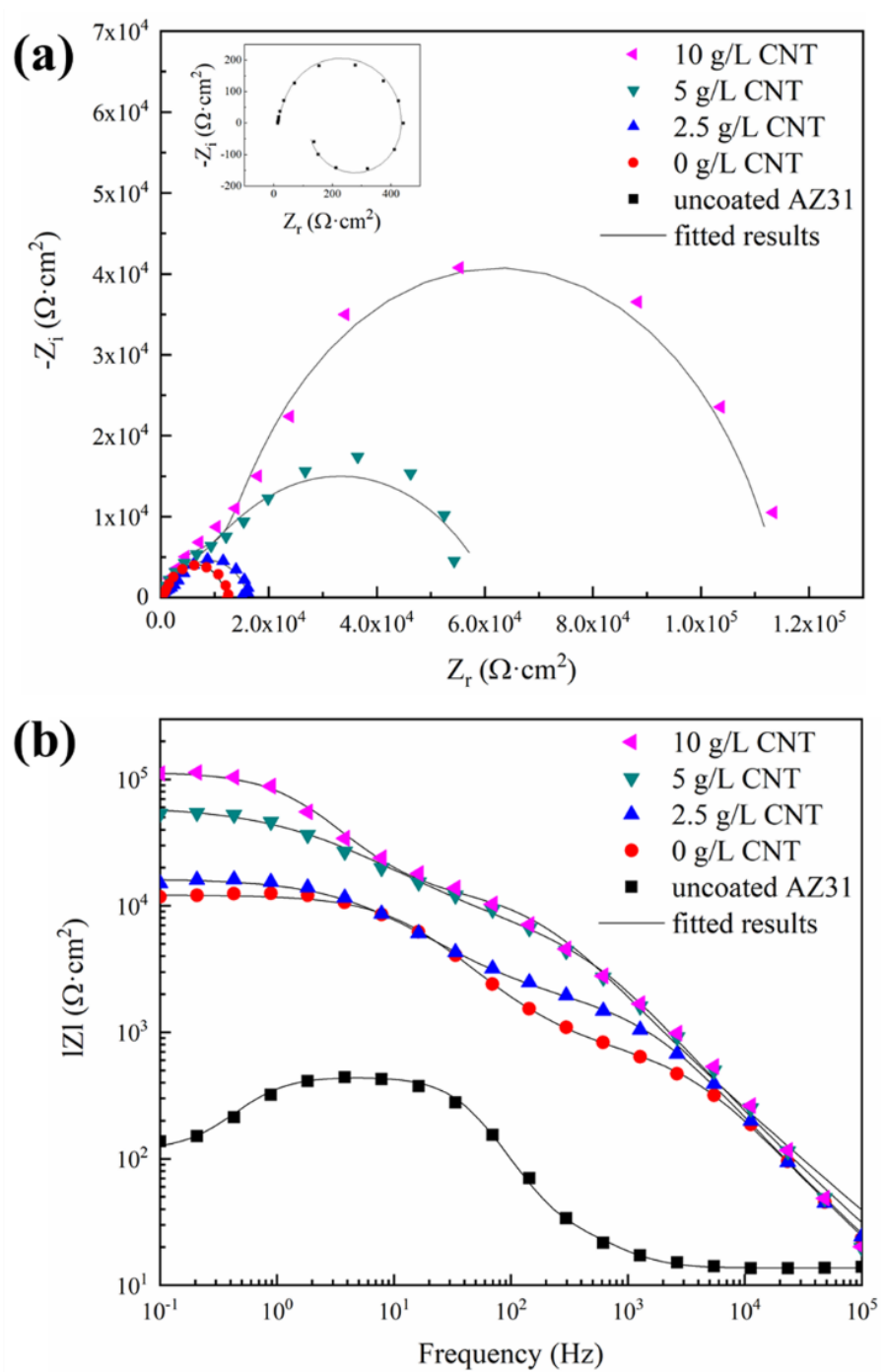

(c)

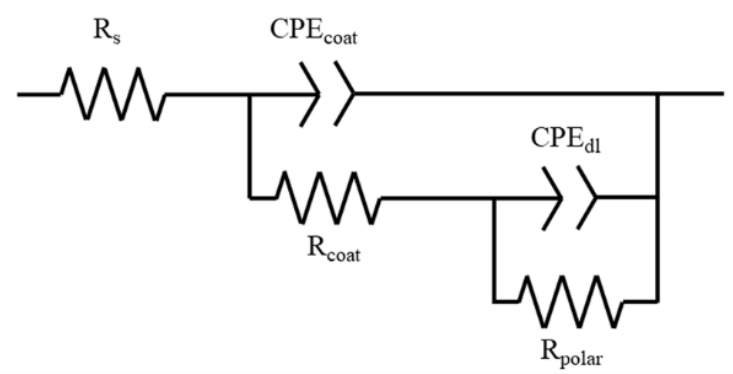

Figure 10. Electrochemical impedance behavior of the PEO coatings in different concentration of CNT:

(a) Nyquist plot; (b) Bode plot; and (c) equivalent circuit.

The fitting data using the equivalent circuit shown in Figure 10c are generally in agreement with the measured data, and the fitting valuesof the equivalent circuit components are shown in Table 3. As the amount of CNT added to the electrolytic solution increases, the value of $R_{\text {coat }}$ and $R_{\text {polar }}$ increase. When the CNT additive is added, porosity decreases and microcracks become finer in the PEO-coating layer. Furthermore, the presence of CNT in the corroding channel interferes with the conduction flow of ions, resulting in increased $\mathrm{R}_{\text {coat }}$. In addition, the CNT suppresses penetration of the corrosive ions into the magnesium substrate, so that the $R_{\text {polar }}$ is increased. 
Table 3. Equivalent circuit parameters from fitted Electrochemical Impedance Spectroscopy (EIS) results of PEO coatings formed in the electrolytes containing different amounts of CNT.

\begin{tabular}{|c|c|c|c|c|c|c|}
\hline Sample & $\begin{array}{c}R_{\text {coat }} \\
\left(\Omega \cdot \mathrm{cm}^{2}\right)\end{array}$ & $\begin{array}{c}\mathrm{CPE}_{\text {coat }} \\
\left(\Omega \cdot \cdot^{-1} \cdot \mathrm{s}^{\mathrm{n}} \cdot \mathrm{cm}^{-2}\right)\end{array}$ & $\mathbf{n}_{\text {coat }}$ & $\begin{array}{c}R_{\text {polar }} \\
\left(\Omega \cdot \mathrm{cm}^{2}\right)\end{array}$ & $\begin{array}{c}\mathrm{CPE}_{\mathrm{dl}} \\
\left(\Omega \cdot \cdot^{-1} \cdot \mathrm{s}^{\mathrm{n}} \cdot \mathrm{cm}^{-2}\right)\end{array}$ & $\mathrm{n}_{\mathrm{dl}}$ \\
\hline $0 \mathrm{~g} / \mathrm{L} \mathrm{CNT}$ & $9.47 \times 10^{2}$ & $6.37 \times 10^{-8}$ & 0.79 & $1.13 \times 10^{4}$ & $2.99 \times 10^{-9}$ & 0.78 \\
\hline $2.5 \mathrm{~g} / \mathrm{L} \mathrm{CNT}$ & $2.09 \times 10^{3}$ & $5.25 \times 10^{-8}$ & 0.80 & $1.43 \times 10^{4}$ & $3.23 \times 10^{-9}$ & 0.69 \\
\hline $5 \mathrm{~g} / \mathrm{L} \mathrm{CNT}$ & $7.60 \times 10^{3}$ & $3.60 \times 10^{-8}$ & 0.81 & $5.43 \times 10^{5}$ & $1.04 \times 10^{-9}$ & 0.60 \\
\hline $10 \mathrm{~g} / \mathrm{L} \mathrm{CNT}$ & $1.60 \times 10^{4}$ & $3.97 \times 10^{-8}$ & 0.78 & $9.87 \times 10^{5}$ & $3.21 \times 10^{-9}$ & 0.86 \\
\hline
\end{tabular}

\subsection{Heat-Dissipation Property of PEO Coatings}

The heat flux of uncoated AZ31 and PEO coatings formed on the AZ31 Mg alloy specimens at different concentrations of CNT is shown in Figure 11. The heat flux of uncoated magnesium substrate was measured as $4317 \mathrm{~W} / \mathrm{m}^{2}$. Higher heat flux than expected could be attributed to increasing emissivity by surface oxidation by the temperature of the setup and roughness due to polishing. The heat flux of the PEO-coating layer increased to $4700,4748,4924$, and $5188 \mathrm{~W} / \mathrm{m}^{2}$ as the addition amount of CNT increased to $0,2.5,5$, and $10 \mathrm{~g} / \mathrm{L}$, respectively. This increase in the heat flux is presumably due to the increase in the thermal conductivity by the CNT with high thermal conductivity in the PEO-coating layer, the decrease of the thickness of the PEO ceramic coatings that interfere with the thermal conduction, and the increase in the emissivity by CNT with high emissivity located on the coating surface.

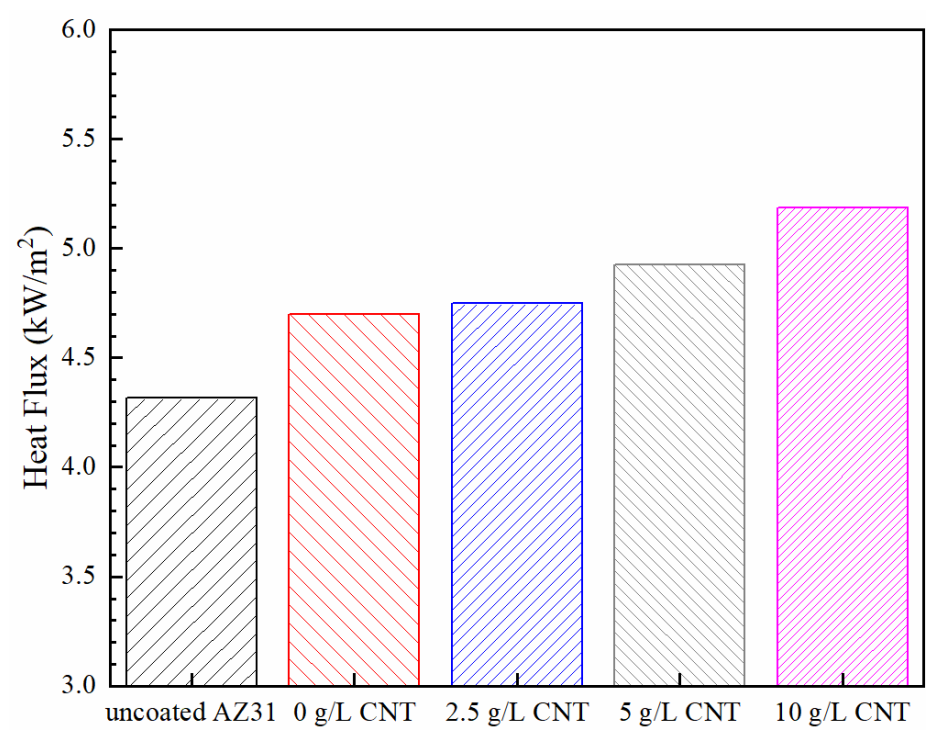

Figure 11. Heat flux of the AZ31 Mg substrate and the PEO coatings in different concentrations of CNT.

Figure 12 shows the emissivity of AZ31 Mg alloys and PEO films with and without CNT additives in the electrolyte. The AZ31 magnesium substrate had a low emissivity value of 0.298 in 5-20 $\mu$ m due to poor photon-emission efficiency from the surface. An emissivity higher than the reported emissivity of $\sim 0.13$ appeared to occur due to surface oxidation and roughness from polishing [41,42]. In contrast, the emissivity of the PEO-coated sample without CNT was 0.818 . Despite significantly higher emissivity compared to the emissivity of the substrate, the thermal-radiation performance of the PEO film without CNT is hampered by high reflectivity. The emissivity of the CNT-added PEO film was measured to be 0.867. The PEO film with $10 \mathrm{~g} / \mathrm{L}$ CNT additive, and a dark surface from incorporating a large amount of CNT, showed the highest emissivity due to the effect of high-emissivity CNT. In particular, the addition of CNT significantly increased emissivity in the range of 5-8 $\mu \mathrm{m}$. The emissivity-enhancement effect of CNT in this study is similar to the effects reported in the literature [43]. 


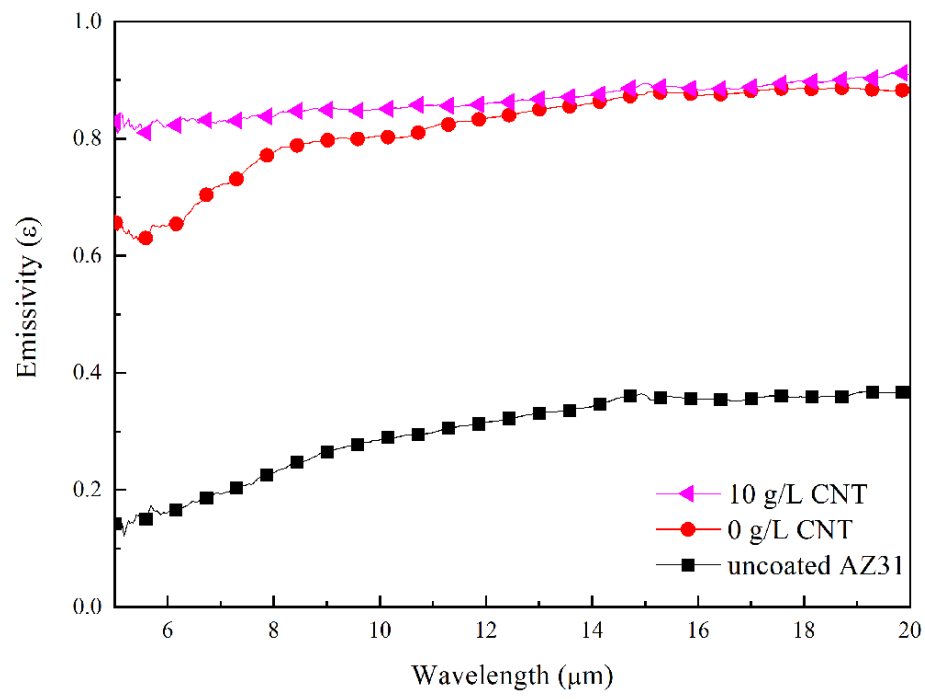

Figure 12. Emissivity of PEO coatings with and without CNT and the AZ31 Mg substrate measured at $100{ }^{\circ} \mathrm{C}$, via Fourier transform infrared spectroscopy (FT-IR). Figure 13 shows the heat-transfer mechanism of the PEO coating with and without CNT additive. The thermal conductivity of $\mathrm{MgO}$ acting as an thermal insulator in the coating layer was quite low, at about $30 \mathrm{~W} \cdot \mathrm{m}^{-1} \cdot \mathrm{k}^{-1}$ [44]. However, the composite PEO coating could improve thermal conductivity by incorporating a CNT additive with high thermal conductivity $\left(2000-6000 \mathrm{~W} \cdot \mathrm{m}^{-1} \cdot \mathrm{k}^{-1}\right)$ into the oxide layer [45]. In addition, the PEO coating with a CNT additive has a thin and dense structure. When the thickness of the coating was thin, the distance of the heat-conduction path having low thermal conductivity was shortened. The size of the pore band also decreased, and the area of the heat-obstructing vacancies was reduced, thereby exhibiting improvement in heat-conductive ability. When the heat is transferred to the coating surface, a high emissivity oxide coating with a CNT additive caused a large amount of thermal radiation, which improved the heat-dissipation capability of the PEO coating.
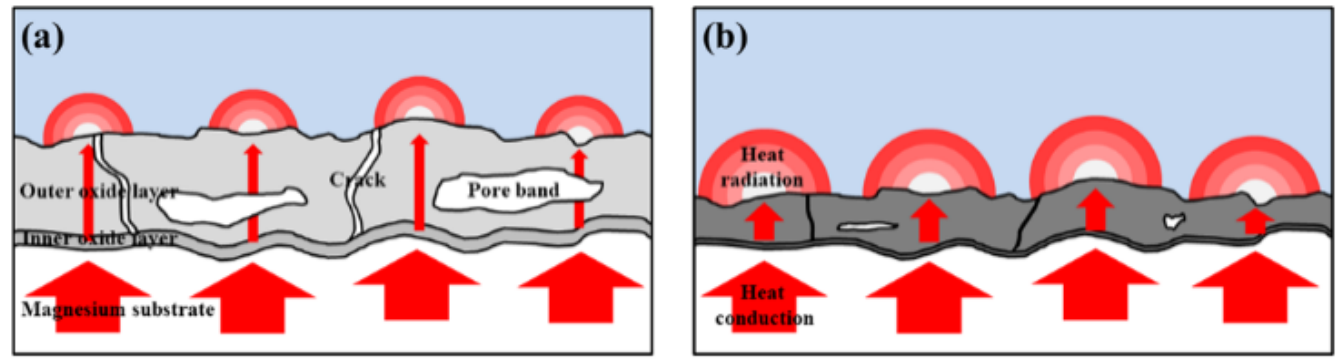

Figure 13. Schematic diagram of the heat-transfer mechanism of the PEO coatings with and without CNT additive: (a) the PEO coating without CNT additive and (b) the PEO coatings with CNT additive.

\section{Conclusions}

This study investigated the influence of different concentrations of CNT in the PEO coating of an AZ31 Mg alloy on corrosion-resistance and thermal-radiation properties. The CNT additive was incorporated into the oxide film by electrophoresis and agitation during the PEO process. The addition of high-conductivity CNT increased the electrical conductivity of the electrolyte and reduced breakdown voltage. A small-sized microarc occurred during the PEO process, resulting in a dense PEO coating. The thin and dense PEO coating with a large amount of CNT additive exhibited surpassing corrosion resistance in potentiodynamic and EIS experiments. The property of high heat dissipation was obtained by the incorporation of CNT with high thermal conductivity. In addition, high thermal conductivity can be expected with a thin and dense film structure.

Supplementary Materials: The following is available online at http:/ /www.mdpi.com/1996-1944/11/12/2438/s1, Figure S1: Schematic diagram of the heat flux measurement setup. 
Author Contributions: Conceptualization, M.H.; Methodology, M.H.; Software, M.H.; Validation, W.C. and M.H.; Formal Analysis, M.H.; Investigation, M.H.; Resources, W.C.; Data Curation, M.H.; Writing-Original Draft Preparation, M.H.; Writing-Review \& Editing, M.H. and W.C.; Visualization, M.H.; Supervision, W.C.; Project Administration, W.C.; Funding Acquisition, W.C.

Funding: This research was funded by National Research Foundation of Korea, grant number NRF-2016R1D1A1B04935380.

Conflicts of Interest: The authors declare no conflict of interest.

\section{References}

1. Mordike, B.L.; Ebert, T. Magnesium: Properties-Applications-Potential. Mater. Sci. Eng. A 2001, 302, $37-45$. [CrossRef]

2. Shu, D.W.; Ahmad, I. Magnesium Alloys: An Alternative for Aluminium in Structural Applications. Adv. Mater. Res. 2011, 168, 1631-1635. [CrossRef]

3. Hollstein, F.; Wiedemann, R.; Scholz, J. Characteristics of PVD-coatings on AZ31hp magnesium alloys. Surf. Coat. Technol. 2003, 162, 261-268. [CrossRef]

4. Gray, J.E.; Luan, B. Protective coatings on magnesium and its alloys-A critical review. J. Alloys Compd. 2002, 336, 88-113. [CrossRef]

5. Blawert, C.; Dietzel, W.; Ghali, E.; Song, G. Anodizing Treatments for Magnesium Alloys and Their Effect on Corrosion Resistance in Various Environments. Adv. Eng. Mater. 2006, 8, 511-533. [CrossRef]

6. Yerokhin, A.L.; Nie, X.; Leyland, A.; Matthews, A.; Dowey, S.J. Plasma electrolysis for surface engineering. Surf. Coat. Technol. 1999, 122, 73-93. [CrossRef]

7. Arrabal, R.; Matykina, E.; Hashimoto, T.; Skeldon, P.; Thompson, G. Characterization of AC PEO coatings on magnesium alloys. Surf. Coat. Technol. 2009, 203, 2207-2220. [CrossRef]

8. Ghasemi, A.; Raja, V.S.; Blawert, C.; Dietzel, W.; Kainer, K. Study of the structure and corrosion behavior of PEO coatings on AM50 magnesium alloy by electrochemical impedance spectroscopy. 2008, 202, 3513-3518.

9. Shim, G. Factors Influencing Plasma Electrolytic Oxidation (PEO) Coatings on Magnesium Alloys: A Review. J. Korean Inst. Met. Mater. 2017, 55, 296-307. [CrossRef]

10. Bergman, T.L.; Incropera, F.P. Fundamentals of Heat and Mass Transfer; Wiley: Hoboken, NJ, USA, 2011.

11. Hamada, T.; Suzuki, T.; Ishiwa, M. Backlight unit and liquid crystal display device having the same. U.S. Patent 7,488,104, 2009.

12. Yu, S.-H.; Jang, D.; Lee, K.-S. Effect of radiation in a radial heat sink under natural convection. Int. J. Heat Mass Transf. 2012, 55, 505-509. [CrossRef]

13. Tsai, W.-Y.; Huang, G.-R.; Wang, K.-K.; Chen, C.-F.; Huang, J. High Thermal Dissipation of Al Heat Sink When Inserting Ceramic Powders by Ultrasonic Mechanical Coating and Armoring. Materials 2017, 10, 454. [CrossRef] [PubMed]

14. Park, K.; Choi, D.-H.; Lee, K.-S. Numerical Shape Optimization for High Performance of a Heat Sink with Pin-Fins. Numer. Heat Transf. A-Appl. 2004, 46, 909-927. [CrossRef]

15. Chu, K.; Wu, Q.; Jia, C.; Liang, X.; Nie, J.; Tian, W.; Gai, G.; Guo, H. Fabrication and effective thermal conductivity of multi-walled carbon nanotubes reinforced $\mathrm{Cu}$ matrix composites for heat sink applications. Compos. Sci. Technol. 2010, 70, 298-304. [CrossRef]

16. Bornoff, R.; Parry, J. An additive design heatsink geometry topology identification and optimisation algorithm. In Proceedings of the 2015 31st Thermal Measurement, Modeling and Management Symposium (SEMI-THERM), San Jose, CA, USA, 15-19 March 2015; pp. 303-308.

17. Tiihonen, T. Stefan-Boltzmann Radiation on Non-convex Surfaces. Math. Methods Appl. Sci. 1998, $20,47-57$. [CrossRef]

18. Mi, J.; Grant, P.S. Modelling the shape and thermal dynamics of Ni superalloy rings during spray forming. Part 2: Thermal modelling-Heat flow and solidification. Acta Mater. 2008, 56, 1597-1608. [CrossRef]

19. Siegel, R. Thermal Radiation Heat Transfer, 4th ed.; Taylor and Francis: Didcot, UK, 2001.

20. Mizuno, K.; Ishii, J.; Kishida, H.; Hayamizu, Y.; Yasuda, S.; Futaba, D.N.; Yumura, M.; Hata, K. A black body absorber from vertically aligned single-walled carbon nanotubes. Proc. Natl. Acad. Sci. USA 2009, 106, 6044. [CrossRef] 
21. Lee, J.; Kim, D.; Choi, C.-H.; Chung, W. Nanoporous anodic alumina oxide layer and its sealing for the enhancement of radiative heat dissipation of aluminum alloy. Nano Energy 2017, 31, 504-513. [CrossRef]

22. Singh, B.; Nayak, S.; Samal, S.; Besra, L.; Bhattacharjee, S. Characterization and Dispersion of Multiwalled Carbon Nanotubes (MWCNTs) in Aqueous Suspensions: Surface Chemistry Aspects. J. Dispers. Sci. Technol. 2012, 33, 1021-1029. [CrossRef]

23. Lee, K.M.; Ko, Y.G.; Shin, D.H. Incorporation of carbon nanotubes into micro-coatings film formed on aluminum alloy via plasma electrolytic oxidation. Mater. Lett. 2011, 65, 2269-2273. [CrossRef]

24. Barati Darband, G.; Aliofkhazraei, M.; Hamghalam, P.; Valizade, N. Plasma electrolytic oxidation of magnesium and its alloys: Mechanism, properties and applications. J. Magnes. Alloys 2017, 5, 74-132. [CrossRef]

25. Liang, J.; Guo, B.; Tian, J.; Liu, H.; Zhou, J.; Liu, W.; Xu, T. Effects of $\mathrm{NaAlO}_{2}$ on structure and corrosion resistance of microarc oxidation coatings formed on AM60B magnesium alloy in phosphate-KOH electrolyte. Surf. Coat. Technol. 2005, 199, 121-126. [CrossRef]

26. Weiping, L.; Liqun, Z.; Yihong, L. Electrochemical oxidation characteristic of AZ91D magnesium alloy under the action of silica sol. Surf. Coat. Technol. 2006, 201, 1085-1092. [CrossRef]

27. Curran, J.A.; Clyne, T.W. Porosity in plasma electrolytic oxide coatings. Acta Mater. 2006, 54, $1985-1993$. [CrossRef]

28. Khaselev, O.; Weiss, D.; Yahalom, J. Anodizing of pure magnesium in $\mathrm{KOH}$-aluminate solutions under sparking. J. Electrochem. Soc. 1999, 146, 1757-1761. [CrossRef]

29. Duan, H.; Yan, C.; Wang, F. Effect of electrolyte additives on performance of plasma electrolytic oxidation films formed on magnesium alloy AZ91D. Electrochimi. Acta 2007, 52, 3785-3793. [CrossRef]

30. Lv, G.; Gu, W.; Chen, H.; Feng, W.; Khosa, M.L.; Li, L.; Niu, E.; Zhang, G.; Yang, S.-Z. Characteristic of ceramic coatings on aluminum by plasma electrolytic oxidation in silicate and phosphate electrolyte. Appl. Surf. Sci. 2006, 253, 2947-2952. [CrossRef]

31. Lu, X.; Blawert, C.; Scharnagl, N.; Kainer, K.U. Influence of incorporating $\mathrm{Si}_{3} \mathrm{~N}_{4}$ particles into the oxide layer produced by plasma electrolytic oxidation on AM50 Mg alloy on coating morphology and corrosion properties. J. Magnes. Alloys 2013, 1, 267-274. [CrossRef]

32. Lu, X.; Sah, S.P.; Scharnagl, N.; Störmer, M.; Starykevich, M.; Mohedano, M.; Blawert, C.; Zheludkevich, M.L.; Kainer, K.U. Degradation behavior of PEO coating on AM50 magnesium alloy produced from electrolytes with clay particle addition. Surf. Coat. Technol. 2015, 269, 155-169. [CrossRef]

33. Song, G.-L. Corrosion of Magnesium Alloys; Woodhead Publishing: Philadelphia, PA, USA, 2011.

34. Stachurski, Z.H. On Structure and Properties of Amorphous Materials. Materials 2011, 4, 1564-1598. [CrossRef]

35. Durdu, S.; Aytac, A.; Usta, M. Characterization and corrosion behavior of ceramic coating on magnesium by micro-arc oxidation. J. Alloys Compd. 2011, 509, 8601-8606.

36. Hussein, R.; Nie, X.; Northwood, D. Plasma electrolytic oxidation coatings on Mg-alloys for improved wear and corrosion resistance. In Corrosion: Material Performance and Cathodic Protection; WIT Press: Ashurst, UK, 2017; pp. 133-147.

37. Smith, G.C. Evaluation of a simple correction for the hydrocarbon contamination layer in quantitative surface analysis by XPS. J. Electron Spectrosc. Relat. Phenom. 2005, 148, 21-28. [CrossRef]

38. Ago, H.; Kugler, T.; Cacialli, F.; Salaneck, W.R.; Shaffer, M.S.P.; Windle, A.H.; Friend, R.H. Work Functions and Surface Functional Groups of Multiwall Carbon Nanotubes. J. Phys. Chem. B 1999, 103, 8116-8121. [CrossRef]

39. Hong, C.-E.; Lee, J.-H.; Kalappa, P.; Advani, S.G. Effects of oxidative conditions on properties of multi-walled carbon nanotubes in polymer nanocomposites. Compos. Sci. Technol. 2007, 67, 1027-1034. [CrossRef]

40. Hirschorn, B.; Orazem, M.E.; Tribollet, B.; Vivier, V.; Frateur, I.; Musiani, M. Determination of effective capacitance and film thickness from constant-phase-element parameters. Electrochim. Acta 2010, 55, 6218-6227. [CrossRef]

41. Huang, Z.; Zhou, W.; Tang, X.; Zhu, D.; Luo, F. Effects of substrate roughness on infrared-emissivity characteristics of Au films deposited on Ni alloy. Thin Solid Films 2011, 519, 3100-3106. [CrossRef]

42. Cverna, F.; ASM International; Materials Properties Database Committee. ASM Ready Reference; ASM International: Materials Park, OH, USA, 2002. 
43. Kim, Y.S.; Yang, H.W.; Shin, K.R.; Ko, Y.G.; Shin, D.H. Heat dissipation properties of oxide layers formed on $7075 \mathrm{Al}$ alloy via plasma electrolytic oxidation. Surf. Coat. Technol. 2015, 269, 114-118. [CrossRef]

44. Slifka, A.; Filla, B.; Phelps, J. Thermal Conductivity of Magnesium Oxide from Absolute, Steady-State Measurements. J. Res. Natl. Inst. Stand. Technol. 1998, 103, 357-363. [CrossRef]

45. Han, Z.; Fina, A. Thermal conductivity of carbon nanotubes and their polymer nanocomposites: A review. Prog. Polym. Sci. 2011, 36, 914-944. [CrossRef]

(c) (1) 